\title{
Fertilizing ability of semen from rams of high- and low-prolificacy flocks
}

\author{
R. W. Moore and D. Whyman* \\ Whatawhata Hill Country Research Station, Ministry of Agriculture and Fisheries, \\ Private Bag, Hamilton, New Zealand
}

\begin{abstract}
Summary. The difference between fresh undiluted ram semen from high $(\mathbf{H})$ and low (L) prolificacy Romney selection lines in success in fertilizing artifically inseminated Romney, half-Romney and Cheviot ewes (unrelated and randomly allocated) was examined in 3 experiments. For ewes producing natural multiple ovulations, the fertilization rate was $71 \%(40 / 56)$ and $40 \%(20 / 50)$ for semen from $\mathrm{H}$ rams and $\mathrm{L}$ rams respectively $(P<0.01)$. Fertilization rates for PMSG-induced multipleovulating ewes were $61 \%(11 / 18)$ for $\mathrm{H}$ semen and $22 \%(4 / 18)$ for $\mathrm{L}$ semen $(P>$ $0.05)$. Values for single-ovulating ewes were $52 \%(35 / 67)$ for $\mathrm{H}$ semen and $50 \%$ $(28 / 56)$ for $\mathrm{L}$ semen $(P>0.05)$.
\end{abstract}

\section{Introduction}

There are many reports in the literature of a direct effect of the ram on the multiple birth rate of ewes to which it has been mated (see reviews of Turner, 1969; Bradford, 1972). Vakil, Botkin \& Roehrkasse (1968) showed that this ram effect was correlated with the prolificacy of the female relatives. It was suggested by Bradford (1972) that rams may contribute to variation in the litter size of their mates through differences in the fertilizing capacity of their semen or in the pre-natal survival of their offspring.

This study examined differences in fertilizing capacity of ram semen taken from the high $(\mathrm{H})$ and low (L) lines of Romney flocks which have been selectively bred for and against multiple births for 30 years (Wallace, 1958). The average litter size in the $\mathrm{H}$ and $\mathrm{L}$ lines during the period 1967-1970 was 1.62 and $1 \cdot 13$ respectively (Clarke, 1972).

\section{Materials and Methods}

Three experiments using unrelated ewes were carried out during 3 consecutive breeding seasons. In Exp. 1 the comparison of semen from $\mathrm{H}$ and $\mathrm{L}$ rams was superimposed on an investigation of hormone effects (Whyman \& Moore, 1980). Of 78 Romney ewes, 38 were injected intramuscularly with 1500 i.u. PMSG (Paynes \& Bryne Ltd) on Day 12 of the oestrous cycle (Day $0=$ day of oestrus). Two days later, 19 of the untreated and 19 PMSG-treated ewes were injected i.m. with $100 \mu \mathrm{g}$ prostaglandin (PG) F-2 $\alpha$ analogue, Cloprostenol (ICI 80,996). Harnessed vasectomized rams were run continuously with the ewes which were checked daily for crayon mating marks at 06:00 and 18:00 h. In Exp. 2 oestrus was synchronized in 64 Romney and 8 Romney $\times$ Border Leicester ewes by the insertion of vaginal sponges

\footnotetext{
- Present address: South Pacific Commission, Post Box D.5, Noumea Cedex, New Caledonia.
} 
impregnated with $30 \mathrm{mg}$ Cronolone (Searle) for 14 days. After 2 weeks vasectomized rams were introduced and oestrous activity was recorded as in Exp. 1. In Exp. 3 oestrus was similarly synchronized in 65 Romney, 67 half-Romney, 17 Cheviot and 12 Drysdale ewes in 3 randomly selected cohorts. The cohorts were synchronized at different times to obtain a convenient number of ewes for artificial insemination at one time. The second oestrus after sponge withdrawal was recorded as in Exp. 1.

All ewes showing oestrus within a $12 \mathrm{~h}$ period were allocated randomly to an individual $\mathrm{H}$ ram (Nos 1-7) or L ram (Nos 8-13) and were artificially inseminated with fresh undiluted semen obtained by means of an artificial vagina (Salamon, 1976). The semen was obtained from Rams 1, 2, 3, 8 and 9 in Exp. 1, and from Rams 2, 4, 8 and 10 in Exp. 2. Microscopical examination was used to grade the sperm motility on a scale of 1 to 8 . The percentage of normal spermatozoa was also determined for each ejaculate in Exp. 1. In Exps 1 and 2 the ewes were artificially inseminated with $500 \times 10^{6}$ spermatozoa within $12 \mathrm{~h}$ after the onset of oestrus and another insemination was given $12 \mathrm{~h}$ later. In Exp. 3 the ewes were allocated randomly to one of the following insemination regimens: Group 1, $500 \times 10^{6}$ spermatozoa $0-12 \mathrm{~h}$ after the onset of oestrus; Group 2, $500 \times 10^{6}$ spermatozoa 12-24 h after the onset of oestrus; Group 3, $250 \times$ $10^{6}$ spermatozoa $0-12$ and $12-24 \mathrm{~h}$ after onset of oestrus; Group 4, $500 \times 10^{6}$ spermatozoa 0-12 and 12-24 h after onset. Ewes in Groups 1, 2 and 3 received semen from one of Rams 5, 6, $7,11,12$ and 13, while those in Group 4 received semen from either Ram 7 or 10.

There were two errors in obtaining the numbers of spermatozoa required for artificial insemination. First, the error in the estimation of the sperm concentration of an ejaculate from a measure of absorbance in a colorimeter following calibration against haemocytometer counts (Bangs \& Underwood, 1948). The maximum error was $\pm 5 \%$. Second, there was a possible error in measuring the required volume of the ejaculate; for this the maximum error was $\pm 7 \%$. The total possible error was therefore $\pm 12 \%$.

All ewes were killed 2-4 days after the onset of oestrus and the number of corpora lutea (CL) was recorded. The oviducts of each ewe were flushed with saline $(9 \mathrm{~g} \mathrm{NaCl} / \mathrm{l})$. When those flushed resulted in the recovery of fewer ova than the number of $C L$, the uterine horns were also flushed. In Exp. 3, all eggs which failed to cleave were fixed and stained as described by Tervit (1973) and examined for metaphase II plates to confirm the lack of fertilization.

Ewes from which at least 1 fertilized ovum was recovered were classified as fertilized, whereas those in which only unfertilized one-celled eggs were found were classified as unfertilized. For the purposes of the assessment of incomplete or partial fertilizations, twin-ovulating ewes from which both ova were recovered were classified as 'fertilized' when both eggs were fertilized, 'incomplete fertilization' when only 1 egg was fertilized, and 'unfertilized' when neither egg was fertilized.

Logit transformation (Nelder \& Wedderburn, 1972) was applied to the data comparing the ewe fertilization rates (no. of ewes fertilized/total no. of ewes classified) inseminated with $\mathrm{H}$ or $\mathrm{L}$ ram semen according to whether the ewes had single ovulations, multiple ovulations, or multiple ovulations induced by PMSG.

\section{Results}

The only significant difference in semen quality traits found between $\mathrm{H}$ and $\mathrm{L}$ rams was a higher sperm concentration for $\mathrm{H}$ semen in Exp. $2\left(3950 \times 10^{6}\right.$ compared with $\left.2800 \times 10^{6} \mathrm{ml}\right)$ but this difference was based on only 2 rams of each type. There was also no correlation between semen quality traits and ewe fertilization rates within ram types.

The numbers of ova recovered/total CL counted were recorded in all experiments for ewes with multiple or single ovulations. In Exp. 1, the rate for multiple ovulations induced by PMSG was calculated separately. Although there was no difference in Exps 1,2 and 3 in the recovery 
rates of natural single and multiple ovulations (78 and $81 \%$ respectively), only $60 \%$ of eggs was recovered from PMSG-treated ewes with multiple ovulations in Exp. 1. There was no difference in the recovery rates from ewes inseminated by semen from the two types of rams in any of the experiments, whatever the ovulation number.

The effects of the different hormonal treatments on ewe fertilization rates in Exp. 1 have been described elsewhere (Whyman \& Moore, 1980); there was a significant reduction in fertilization rate in ewes treated with PMSG but there was no such effect in the cloprostenol-treated ewes. Therefore the treatment with cloprostenol was ignored when the effect of type of semen on ewe fertilization rate was examined.

In Exp. 3 there were only 2 one-celled eggs for which fertilization failure was not confirmed by staining. There were no significant differences in the results for the 4 groups (Table 1), and comparisons of type of semen effects on ewe fertilization rates were therefore carried out ignoring the presence of the 4 insemination regimens.

Table 1. Fertilization rates (no. of ewes fertilized/total no. classified) for ewes in Exp. 3 receiving different insemination regimens

\begin{tabular}{|c|c|c|c|c|c|c|c|c|}
\hline & \multicolumn{4}{|c|}{ Single ovulations } & \multicolumn{4}{|c|}{ Multiple ovulations } \\
\hline & Group 1 & Group 2 & Group 3 & Group 4 & Group 1 & Group 2 & Group 3 & Group 4 \\
\hline All $\mathrm{H}$ rams & $2 / 10$ & $6 / 11$ & $9 / 11$ & $3 / 6$ & $8 / 11$ & $8 / 12$ & $8 / 13$ & $5 / 6$ \\
\hline All $\mathrm{L}$ rams & $7 / 8$ & $5 / 10$ & $6 / 7$ & $4 / 7$ & $6 / 12$ & $4 / 10$ & $5 / 11$ & $0 / 3$ \\
\hline Total \% & 50 & 52 & 83 & 54 & 61 & 55 & 54 & 56 \\
\hline
\end{tabular}

Table 2. Fertilization rates (no. of ewes fertilized/total no. classified) for ewes inseminated with semen from rams of high $(\mathrm{H})$ or low (L) prolificacy (no. of ram in parentheses)

\begin{tabular}{|c|c|c|c|c|c|c|}
\hline \multirow[b]{3}{*}{ Experiment } & \multicolumn{4}{|c|}{ Ewes with natural ovulations } & \multirow{2}{*}{\multicolumn{2}{|c|}{$\begin{array}{l}\text { Ewes with PMSG-inducec } \\
\text { multiple ovulations }\end{array}$}} \\
\hline & \multicolumn{2}{|c|}{ Single } & \multicolumn{2}{|c|}{ Multiple } & & \\
\hline & H rams & L rams & $\mathrm{H}$ rams & L rams & H rams & L rams \\
\hline 1 & $\begin{array}{l}\text { (1) } 1 / 1 \\
\text { (2) } 1 / 3 \\
\text { (3) } 2 / 3\end{array}$ & $\begin{array}{l}\text { (8) } 2 / 2 \\
\text { (9) } 1 / 5\end{array}$ & $\begin{array}{l}\text { (1) } 4 / 5 \\
\text { (2) } 4 / 4 \\
\text { (3) } 1 / 2\end{array}$ & $\begin{array}{l}\text { (8) } 4 / 5 \\
\text { (9) } 1 / 1\end{array}$ & $\begin{array}{l}\text { (1) } 4 / 8 \\
\text { (2) } 7 / 9 \\
\text { (3) } 0 / 1\end{array}$ & $\begin{array}{l}\text { (8) } 3 / 9 \\
\text { (9) } 1 / 9\end{array}$ \\
\hline Total \% & 51 & 43 & 82 & 83 & 61 & 21 \\
\hline 2 & $\begin{array}{l}\text { (2) } 5 / 10 \\
\text { (4) } 6 / 12\end{array}$ & $\begin{array}{c}\text { (8) } 3 / 7 \\
\text { (10) } 0 / 10\end{array}$ & $\begin{array}{l}\text { (2) } 1 / 2 \\
\text { (4) } 1 / 2\end{array}$ & $\begin{array}{r}\text { (8) } 0 / 4 \\
\text { (10) } 0 / 4\end{array}$ & & \\
\hline Total $\%$ & 50 & 18 & 50 & 0 & & \\
\hline 3 & $\begin{array}{ll}\text { (5) } & 4 / 8 \\
\text { (6) } & 5 / 12 \\
\text { (7) } & 11 / 18\end{array}$ & $\begin{array}{l}\text { (10) } 4 / 7 \\
\text { (11) } 7 / 9 \\
\text { (12) } 5 / 8 \\
\text { (13) } 6 / 8\end{array}$ & $\begin{array}{l}\text { (5) } 9 / 13 \\
\text { (6) } 9 / 12 \\
\text { (7) } 11 / 16\end{array}$ & $\begin{array}{l}\text { (10) } 0 / 3 \\
\text { (11) } 5 / 11 \\
\text { (12) } 6 / 14 \\
\text { (13) } 4 / 8\end{array}$ & & \\
\hline Total \% & 53 & 69 & 70 & 42 & & \\
\hline Overall \% & 52 & 50 & $71^{*}$ & $40^{*}$ & 61 & 21 \\
\hline
\end{tabular}

$* P<0.01$.

Statistical analysis of the data given in Table 2 showed that there was an interaction $(P<$ 0.05 ) between the type of ovulation (single, natural-multiple or PMSG-multiple) and the type of ram semen $(H$ or $\mathbf{L})$. Separate analyses within each type of ovulation were then carried out using 
an appropriate F-test to compare variation between types of semen with the variation within types of semen. For ewes with natural multiple ovulations the fertilization rate for semen from $\mathrm{H}$ rams was greater than that for semen from $\mathrm{L}$ rams $(P<0.01)$. There was no significant difference in fertilization rates for the two types of semen used with ewes having single ovulations or multiple ovulations induced by PMSG.

The incidence of incomplete fertilization in ewes naturally ovulating 2 recovered eggs is shown in Table 3. Incomplete fertilizations occurred at random and were not associated with type of semen or any particular insemination regimen. Overall, 9/46 (20\%) ewes showed incomplete fertilization and this was not significantly different from that of $7 / 14(50 \%)$ for PMSG-treated ewes.

Table 3. Number of eggs fertilized in naturally twin-ovulating ewes from which both eggs were recovered

\begin{tabular}{|c|c|c|c|c|c|c|c|c|c|}
\hline & \multirow{2}{*}{$\begin{array}{c}\text { No. } \\
\text { fertilized }\end{array}$} & \multirow{2}{*}{ Exp. 1} & \multirow{2}{*}{ Exp. 2} & \multicolumn{4}{|c|}{ Exp. 3} & \multirow[b]{2}{*}{ Total } & \multirow{2}{*}{$\begin{array}{l}\text { Incidence of } \\
\text { incomplete } \\
\text { fertilization* }\end{array}$} \\
\hline & & & & Group 1 & Group 2 & Group 3 & Group 4 & & \\
\hline H rams & $\begin{array}{l}2 \\
1 \\
0\end{array}$ & $\begin{array}{l}5 \\
2 \\
1\end{array}$ & $\begin{array}{l}2 \\
0 \\
1\end{array}$ & $\begin{array}{l}3 \\
0 \\
1\end{array}$ & $\begin{array}{l}8 \\
2 \\
4\end{array}$ & $\begin{array}{l}3 \\
1 \\
2\end{array}$ & $\begin{array}{l}3 \\
0 \\
1\end{array}$ & $\begin{array}{r}24 \\
5 \\
10\end{array}$ & $5 / 29$ \\
\hline $\mathrm{L}$ rams & $\begin{array}{l}2 \\
1 \\
0\end{array}$ & $\begin{array}{l}3 \\
1 \\
2\end{array}$ & $\begin{array}{l}0 \\
0 \\
3\end{array}$ & $\begin{array}{l}5 \\
1 \\
3\end{array}$ & $\begin{array}{l}1 \\
1 \\
5\end{array}$ & $\begin{array}{l}4 \\
1 \\
5\end{array}$ & $\begin{array}{l}0 \\
0 \\
2\end{array}$ & $\begin{array}{c}13 \\
4 \\
20\end{array}$ & $4 / 17$ \\
\hline Incidence & incomplete & $\begin{array}{l}\text { rtilization } \\
3 / 11\end{array}$ & $0 / 2$ & $1 / 9$ & $3 / 12$ & $2 / 9$ & $0 / 3$ & & \\
\hline
\end{tabular}

* Among fertilized ewes.

\section{Discussion}

Ewe lambing percentages after artificial insemination with fresh undiluted semen have been reported as $47 \%$ (Lapwood, Martin \& Entwistle, 1972), 55\% (Dunlop, Tallis, Brown \& Gream, 1972 ) and $74 \%$ (Amir \& Schindler, 1972). The average figure of $54 \%$ ewes with fertilized eggs in the present study was rather low, but the reason is unknown.

Our results indicate that the selection for high prolificacy in the female has been accompanied by an enhanced ability of semen from related rams to fertilize the ova shed by ewes ovulating more than one egg, and suggests a mechanism for the direct effect of the ram on multiple birth rate (see Turner, 1969; Bradford, 1972). A positive relationship between prolificacy of female relatives and litter size produced by the ram has been shown previously by Vakil et al. (1968) who found an increase of 0.12 lambs born per ewe lambing to twin-born rams compared with single-born rams. Burfening, Friedrick \& Van Horn (1977) have reported that rams selected for high prolificacy (on the basis of their dams' lambing records) produced more lambs born per randomly selected ewe mated than did rams selected for low prolificacy. This effect was not reflected in any differences in fertilization rates or in embryo deaths but these results may not conflict with our findings because Burfening et al. (1977) did not consider multiple- and single-ovulating ewes separately. Their egg recoveries were 92 and $80 \%$ for the high- and low-prolificacy rams respectively.

Prolificacy differences among breeds have previously been found to be reflected in breed differences in young rams in terms of testis diameters (Land, 1973; Carr \& Land, 1975), plasma LH concentrations (Thimonier, Pelletier \& Land, 1972; Bindon \& Turner, 1974; Carr \& Land, 1975 ) and testis growth following hemicastration (Land \& Carr, 1975). The selection for and 
against multiple births in the two lines used in this study has probably led to line differences in hormonal levels or sensitivities in both sexes and to differences in spermatogenesis. Differences between the two types of ram semen in the ability to fertilize multiple-ovulations could be influenced by a difference between the $\mathrm{H}$ and $\mathrm{L}$ semen in the frequency of incomplete fertilization, but there was no such difference found. However, the incidence of incomplete fertilization $(20 \%)$ in the naturally twin-ovulating ewes was much higher than the figures of $2.4 \%$ previously found by Dr I. D. Killeen (personal communication) and $6.4 \%$ by Restall, Brown, Blockey, Cahill \& Kearins (1976). Incomplete fertilization may be more common following artificial insemination; Dutt (1954) reported a high incidence of incomplete fertilization with artificial insemination but did not give a precise figure. The effect may be due to the stress associated with artificial insemination which could interrupt sperm transport and lead to smaller numbers of spermatozoa reaching the oviducts (Thibault \& Winterberger-Torrès, 1967).

There was no difference in fertilization rates among the 4 insemination regimens in Exp. 3 . This result agrees with that of Amir \& Schindler (1972) who showed no difference in conception rate of ewes inseminated with 300 or $500 \times 10^{6}$ spermatozoa from 0 to $36 \mathrm{~h}$ after the onset of oestrus. There was no effect of double insemination on the success rate of fertilizing twin ovulations as was suggested by Dunlop \& Tallis (1964). This is not surprising as the average interval between multiple ovulations has been shown to be only $1.2 \mathrm{~h}$ (Whyman, Johnson, Knight \& Moore, 1979).

Previous reports of the ram effect (see Ragab \& Asker, 1954; Vakil et al., 1968; Donald, Read \& Russell, 1970) have been obtained using natural mating; our results need confirmation under these conditions, and extension from differences in fertilization rate to differences in lambing rate. Barker \& Land (1970) compared rams of two breeds which differed markedly in litter size and found no direct effect on prolificacy. Therefore differences in prolificacy between two genotypes do not guarantee differences in the ram's ability to produce multiple births. More trials need to be carried out comparing rams from genotypes of defined prolificacy to determine the incidence and economic importance of this phenomenon.

We thank Mrs S. H. Rowe, Mr A. G. Barnes, Mr K. G. Ferris and Mr P. R. Lynch for valuable technical assistance; Dr H. R. Tervit for instructions on staining ova; and Dr D. L. Johnson for the statistical analyses.

\section{References}

Amir, D. \& Schindler, H. (1972) The conception rate of ewes after artificial insemination at different times during oestrus. J. Reprod. Fert. 28, 261-264.

Bangs, C.L. \& Underwood, E.J. (1948) A comparison of methods of estimating sperm concentration in rams' semen. Aust. vet. J. 24, 89-93.

Barker, J.D. \& Land, R.B. (1970) A note on the fertility of hill ewes mated to Finnish Landrace and Border Leicester rams. Anim. Prod. 12, 673-675.

Bindon, B.M. \& Turner, H.N. (1974) Plasma LH of the prepubertal lamb: a possible early indicator of fecundity. J. Reprod. Fert. 39, 85-88.

Bradford, G.E. (1972) Genetic control of litter size in sheep. J. Reprod. Fert., Suppl. 15, 23-41.

Burfening, P.J., Friedrick, R.L. \& Van Horn, J.L. (1977) Estimates of early embryonic loss in ewes mated to rams selected for high and low prolificacy. Theriogenology 7, 285-291.

Carr, W.R. \& Land, R.B. (1975) Plasma luteinizing hormone levels and testis diameters of ram lambs of different breeds. J. Reprod. Fert. 42, 325-333.
Clarke, J.N. (1972) Current levels of performance in the Ruakura fertility flock of Romney sheep. Proc. N.Z. Soc. Anim. Prod. 32, 99-111.

Donald, H.P., Read, J.L. \& Russell, W.S. (1970) Influence of litter size and breed of sire on carcass weight and quality of lambs. Anim. Prod. 12, 281-290.

Dunlop, A.A. \& Tallis, G.M. (1964) The effects of length of oestrus and number of inseminations on the fertility and twinning rate in the Merino ewe. Aust.J. agric. Res. 15, 282-288.

Dunlop, A.A., Tallis, G.M., Brown, G.H. \& Gream, B.D. (1972) The relation of semen and vaginal mucus traits to fertility in the Australia Merino. Aust. $J$. agric. Res. 23, 295-307.

Dutt, R.H. (1954) Fertility rate and embryonic death loss in ewes early in the breeding season. J. Anim. Sci. 13, 464-473.

Land, R.B. (1973) The expression of female sex-limited characters in the male. Nature, Lond. 241, 208-209.

Land, R.B. \& Carr, W.R. (1975) Testis growth and 
plasma LH concentration following hemicastration and its relation with female prolificacy in sheep. $J$. Reprod. Fert. 45, 495-501.

Lapwood, K.R., Martin, I.C.A. \& Entwistle, K.W. (1972) The fertility of Merino ewes artificially inseminated with semen diluted in solutions based on skim milk, glucose or ribose. Aust. J. agric. Res. 23, 457-466.

Nelder, J.A. \& Wedderburn, R.W.M. (1972) Generalized linear models. Jl R. statist. Soc. A 135, 370-384.

Ragab, M.T. \& Asker, A.A. (1954) Twinning in Ossimi Sheep. Emp. J. exp. Agric. 22, 224-230.

Restall, B.J., Brown, G.H., Blockey, M. de B., Cahill, L. \& Kearins, R. (1976) Assessment of reproductive wastage in sheep. I. Fertilization failure and early embryonic survival. Aust. J. exp. Agric. Husb. 16, 329-335.

Salamon, S. (1976) Artificial insemination of sheep, pp. 47-51. Department of Animal Husbandry, University of Sydney.

Tervit, H.R. (1973) Culture and transfer of sheep and cattle ova. Ph.D. thesis, University of Cambridge.

Thibault, C. \& Winterberger-Torrès, S. (1967) Oxytocin and sperm transport in the ewe. Int. J. Fert. 12 , $410-415$.

Thimonier, J., Pelletier, J. \& Land, R.B. (1972) The concentration of plasma $\mathbf{L H}$ in male and female lambs of high and low prolificacy breed types. $J$. Reprod. Fert. 31, 498-499, Abstr.

Turner, H.N. (1969) Genetic improvement of reproduction rate in sheep. Anim. Breed. Abstr. 37, 545-563.

Vakil, D.V., Botkin, M.P. \& Roehrkasse, A.P. (1968) Influence of hereditary and environmental factors on twinning in sheep. J. Hered. 59, 256-259.

Wallace, L.R. (1958) Breeding Romneys for better lambing percentages. N.Z. Jl Agric. 97, 545-550.

Whyman, D. \& Moore, R.W. (1980) Effects of PMSG and the prostaglandin F-2 $\alpha$ analogue, Cloprostenol, on superovulation, fertilization and egg transport in the ewe. J. Reprod. Fert. (in press).

Whyman, D., Johnson, D.L., Knight, T.W. \& Moore, R.W. (1979) Intervals between multiple ovulations in PMSG-treated and untreated ewes and the relationship between ovulation and oestrus. J. Reprod. Fert. 55, 418-488.

Received 28 August 1979 